\title{
Unidad en la diversidad: entre utopías y concreción en investigación desde la educación popular
}

\author{
Unity in diversity: \\ between utopias and concretion in research from popular education \\ Unidade na diversidade: \\ entre utopias e concretudes em pesquisa desde a educação popular
}

Maria Rosa da Silva ${ }^{a}$, Rita de Cássia Lopes ${ }^{a}$,Wander Luiz Reginaldo ${ }^{a}$

${ }^{a}$ Centro Universitario Salesiano de São Paulo, Americana, SP. Brasil.

goncalves.mariarosasilva@gmail.com,rita_ijano@yahoo.com.br,wander.reginaldo@yahoo.com.br

\begin{abstract}
RESUMEN
Este estudio aborda el tema del aislamiento social derivado de la pandemia del Coronavirus (COVID19) a partir de una intervención educativa realizada por estudiantes de la maestría en educación con estudiantes masculinos y femeninos en una clase del curso técnico en recursos humanos y administración de una escuela vocacional ubicada en Limeira / SP. Con el fin de provocar reflexiones y generar motivaciones para nuevas discusiones sobre el momento trascendental que involucra a todos, se inició el estudio con una invitación a los estudiantes a construir y compartir mensajes de solidaridad, paz y buenas prácticas entre ellos de convivencia social en un escenario pandémico, de inseguridad e incertidumbre. El estudio se desarrolló a partir de un marco teórico y de los aportes de la Educación Popular. La conclusión de la investigación se produjo con la divulgación de las construcciones realizadas a través de los recursos audiovisuales y mediante este artículo relato. Pretendemos que, entre los impactos positivos que produce esta investigación, encontremos inspiración para la puesta en marcha de acciones que favorezcan una cultura de paz y solidaridad, de transformación, alteridad y empatía; así también se buscaba provocar la indignación ante las desigualdades que impone en menor o mayor grado de sufrimiento de algunas personas a expensas de otras.
\end{abstract}

Palabras claves: Educación Popular, Cultura de Paz, Pandemia.

\begin{abstract}
This study addresses the theme of social isolation resulting from the Coronavirus pandemic (COVID19) from an intervention carried out by master students in education with male and female students in a technical course class in human resources and administration of a vocational school located in Limeira/SP. With a view to provoking reflections and generating subsidies for new discussions about the epochal moment that involves everyone, the intervention started with an invitation to students to build and share messages of solidarity, peace and good practices among themselves within a social coexistence in a pandemic scenario of insecurities and uncertainties. The study was developed based on a theoretical framework and on the contributions of Popular Education and its conclusion occurred with the disclosure of the constructions made through audiovisual resources and through this article report. We intend that, among the positive impacts produced by this study, we find the inspiration for the implementation of actions in favor of a culture of peace and solidarity and of transformation, alterity and empathy as well as indignation in face of inequalities that imposes a lesser or greater degree suffering to some people at the expense
\end{abstract}

Key words: Popular Education, Culture of Peace, Pandemic. 


\section{RESUMO}

Este estudo aborda a temática do isolamento social decorrente da pandemia do Coronavírus (COVID19) a partir de uma intervenção educativa realizada por mestrandos em educação com alunos e alunas de uma turma de curso técnico de recursos humanos e administração de uma escola profissionalizante situada em Limeira/ SP. Com vistas a provocar reflexões e gerar subsídios para novas discussões acerca do momento epocal que envolve a todos e todas, a intervenção iniciou com um convite aos/às alunos/as para construção e compartilhamento entre si de mensagens de solidariedade, paz e boas práticas de convivência social num cenário pandêmico, de inseguranças e incertezas; desenvolveu-se apoiada em referencial teórico e nas contribuições da Educação Popular e sua conclusão se deu com a divulgação das construções efetivadas através de recurso audiovisual e por meio deste relato de artigo. Intentamos que, entre os impactos positivos produzidos por este estudo, encontremos a inspiração para a concretização de ações a favor de uma cultura de paz e solidariedade e de transformação, alteridade e empatia assim como de indignação frente às desigualdades que impõe menor ou maior grau de sofrimento a algumas pessoas em detrimento de outras.

Palavras-chave: Educação Popular, Cultura de paz, Pandemia.

\section{INTRODUCCIÓN}

Este artículo surgió de un ejercicio de investigación como parte de las actividades propuestas en la disciplina "Metodologías educativas de intervención socio comunitaria" de la maestría en educación del Centro Universitario Salesiano de São Paulo - UNISAL - Americana / SP, cuyo objetivo era ampliar el conocimiento metodológico sobre Intervenciones educativas socio comunitarias, proponiendo intervenciones educativas en las escuelas, instituciones, colectivos y/o movimientos sociales, buscando formarse en y con estos espacios y sujetos; así como también, comprender y analizar las diferentes posibilidades de intervención educativa en los espacios escolares y no escolares.

En esta propuesta, incluso, pretendíamos visitar diferentes lugares, donde pudiéramos realizar nuestras prácticas, reflexiones y estudios con una audiencia previamente definida; sin embargo, nos sorprendió la determinación del aislamiento social en la prevención de COVID-19, decretado en todo el Estado de São Paulo, afectando especialmente a las instituciones educativas y resultando en la interrupción de clases presenciales, la cual culminó en la alternativa de educación a distancia.

Como búsqueda adaptativa, reflexionamos sobre cómo podríamos utilizar herramientas y propuestas alternativas para llevar a cabo nuestras acciones educativas ante un escenario pandémico y decidimos trabajar con un grupo de estudiantes ya $\operatorname{conocidos}^{1}$, con el objetivo de favorecer la realización de este estudio debido al vínculo ya existente. Enfocados en las diversas incógnitas y fragmentaciones que estallaron con la situación actual, pensamos en realizar una intervención que pudiera llamar la atención de las personas; especialmente aquellas atrapadas en una cuarentena vivencial e histórica que no provenía de un Coronavirus, sino de una epidemia de la cual la humanidad ha estado plagada durante mucho tiempo: la indiferencia. Esta que se realiza en la ausencia de percibir, revalorizar y enfatizar al otro en su singularidad y; a partir de esto, crear vínculos de comunicación solidaria y no violenta.

\footnotetext{
El grupo de alumnos ya era conocido por uno de los autores de este artículo, quien imparte clases de materias de gestión y negocios en los cursos a los que asisten. Debido a la proximidad y vínculo ya establecido entre profesor y alumnos, el autor y los autores coincidieron en que mediarían las conversaciones con los alumnos.
} 
Así se concreta la propuesta "Unidad en la diversidad: entre utopías y concreciones en la investigación desde la educación popular". Es decir, partimos de la motivación de una humanidad unida por una pandemia a escala mundial. No obstante, ¿estamos todas las personas viviendo de la misma manera? ¿Con qué eficacia se materializa la utopía de la igualdad?

Esta investigación se basa en un enfoque metodológico cualitativo y los principios de la dialogicidad, cuyos principales referentes son: Larrosa (2002), Jara (2018), Vasconcelos (2020), Freire (2005), Méjia (2014), Streck (2018), Santos (2020). La Educación Popular conlleva la responsabilidad de la mirada crítica situacional, concretada en las relaciones sociales; sin embargo, esta mirada apunta a denunciar y a transformar una realidad muchas veces basada en la indiferencia y la opresión, especialmente de quienes más sufren las desigualdades: los negros, los pueblos indígenas, los pobres y las mujeres.

La trayectoria metodológica constaba de los siguientes pasos: 1) Conexión; 2) Construcción y compartición; 3) Síntesis. La etapa de construcción inicia este ejercicio de investigación invitando a los estudiantes a construir y compartir mensajes de manera efectiva. La etapa de construcción y compartición en común se caracteriza por el desarrollo de esta propuesta; en esta fase se produce la interacción virtual a través de las tecnologías de la comunicación, la creación de mensajes, el envío y la recepción de las construcciones de los estudiantes. La síntesis, la etapa final, se caracteriza por la recopilación de mensajes en un solo archivo y su disposición en presentación audiovisual, Se comprueba también los efectos y sensaciones que surgieron en el grupo. A partir de los datos obtenidos en la relación, participación y experiencia con los sujetos, fue posible establecer un escenario de cómo las personas están viviendo el proceso educativo en el período pandémico.

Ante la situación de aislamiento social y la imposibilidad de contacto directo con comunidades, espacios y otros individuos, definimos como posible estrategia, emprender una acción educativa con un público ya conocido, en un entorno virtual, a través de tecnologías disponibles y accesibles a los participantes. En concreto, el público al cual nos referimos, estaba compuesto por hombres y mujeres, en su mayoría entre 17 y 30 años, estudiantes del curso técnico profesional en recursos humanos (RRHH) y administración (ADM) de una escuela técnica profesional ubicada en la ciudad de Limeira, interior de São Paulo/ SP, con las clases presenciales suspendidas por la prevención del COVID-19.

Con el ambiente y la audiencia definidos, la implementación de este proyecto se dividió en tres etapas distintas: 1) Conexión; 2) Construcción y compartición; 3) Síntesis; descrito más adelante. Esta sistematización permitió un mejor seguimiento y análisis de cada momento de la interacción entre los estudiantes de maestría y los estudiantes participantes en este ejercicio de investigación para lo cual se adoptó una metodología cualitativa anclada en un marco teórico y en los aportes de la educación popular. Según Triviños (1987), la investigación cualitativa se presenta como:

[...] alternativas metodológicas frente al positivismo cuantitativo, no podemos dejar de mencionar que la investigación cualitativa de carácter estructural-funcionalista ha tenido un gran desarrollo, favorecida especialmente en los países del Tercer Mundo por los regímenes políticos que la ven como una forma de preservar el estatus social quo elitista que los caracteriza (p. 117).

Según la cita mencionada, se observa el alcance de la investigación cualitativa, la cual apunta al fenómeno en su singularidad y a la persona en su individualidad en un contexto 
socio-político, económico y social. Según Triviños (1987), es posible enumerar algunas características de la investigación cualitativa: esta se basa en el medio natural como fuente directa de datos y en el investigador como instrumento clave. La investigación cualitativa es descriptiva, se preocupa no solo por el proceso, sino también por el resultado, los datos se analizan inductivamente y se ocupa del significado. La Educación Popular, basada en el principio de problematización y dialogicidad, se preocupa:

[...] por el reflejo de contextos reales, su universo de símbolos, lenguajes, signos e instrumentos encaminados a una acción que tiene como objetivo resolver problemas efectivos, brindando espacios para las construcciones colectivas, cuyas prácticas y conocimientos generados, imbuidos de la diversidad de ideas provenientes de la participación popular, traducen conocimientos distintos a los nunca antes solicitados o considerados y que unidos, forman un adecuado y eficiente "saber hacer" (Torrezan, 2012, p. 26).

Estos aspectos y características, desde el análisis cualitativo desde la perspectiva de la educación popular, orientaron y apoyaron el desarrollo de este estudio.

\subsection{PASO 1: CONEXIÓN}

A este paso de conexión lo llamamos así para representar el momento en que se hizo el primer contacto con el grupo de estudiantes para exponer la demanda. Como se mencionó, el grupo ya era conocido por uno de los autores de este artículo, quien se encargaría de realizar la invitación, ya que, independientemente de la relación profesor-alumno existente, acordamos reforzar que esta no fuese una actividad evaluativa ni contemplada en el currículo; orientación importante para no someterlos a un sentimiento de obligación.

La invitación se hizo a través de la aplicación WhatsApp y consistió en un desafío dirigido al grupo de estudiantes para crear mensajes de solidaridad, paz, acogida, consuelo, buena convivencia en este escenario de caos; y así poder llegar a otras personas en la misma condición de cuarentena, incluso sin presencia física, solo con la ayuda de mensajes electrónicos de aliento. Este gesto voluntario de interrupción, de dejar de pensar, sentir y escuchar al otro es descrito por Larrossa:

La experiencia, la posibilidad de que algo suceda o nos toque, requiere un gesto de interrupción, un gesto que es casi imposible en los tiempos de hoy: requiere detenerse a pensar, detenerse a mirar, detenerse a escuchar, pensar más despacio, mirar más, despacio y escuchar más despacio; parar para sentir, sentir más despacio, detenerse en los detalles, suspender la opinión, suspender el juicio, suspender la voluntad, suspender el automatismo de la acción, cultivar la atención y la delicadeza, abrir los ojos y los oídos, hablar de lo Nos pasa, aprender la lentitud, escuchar a los demás, cultivar el arte del encuentro, estar muy tranquilos, tener paciencia y darnos tiempo y espacio (Larrosa, 2002, p. 5).

Por ello, buscamos brindar a los participantes oportunidades para practicar la empatía, la solidaridad y la alteridad en situaciones de cuarentena, así como momentos de socialización, constitución de identidad y conciencia colectiva. 
La existencia del vínculo, criterio importante que motivó la elección del grupo, favoreció la exposición de la demanda y la conciencia de su propósito, ya que existía una apertura en la comunicación y familiaridad entre ellos y los autores². Esta conexión brindó una mayor relajación para el intercambio de información, aclaración de dudas sobre el formato de las construcciones -definidas como la libre elección de los participantes- y también para que estos pudieran expresar sus sentimientos y pensamientos sin miedo. El diálogo permitió un ambiente seguro y acogedor, libre de preocupaciones sobre evaluaciones, críticas o desaprobaciones.

Paulo Freire (2005), en su obra Pedagogía del Oprimido, señala que el diálogo "no solo supone la coparticipación y la reciprocidad, sino que, sobre todo, constituye un proceso significativo, el cual es compartido por sujetos iguales entre sí en una relación también de igualdad". Esta relación de igualdad quedó claramente establecida cuando se eliminó de la ecuación la condición alumno/ docente, quedando los elementos esenciales: el ser humano que se sustenta a sí mismo voluntariamente.

\subsection{PASO 2: CONSTRUCCIÓN Y COMPARTICIÓN}

En esta etapa se crearon mensajes electrónicos: poemas, música, videos, parodias, cadenas u otro formato de comunicación y expresión elegido por el alumno. Las herramientas de comunicación accesibles y utilizadas durante las etapas fueron: aplicación WhatsApp mediante la cual oficializamos la invitación y aceptación de los participantes; aplicación de videoconferencia Jitsi Meet para promover reuniones virtuales; correo electrónico predefinido para recibir mensajes.

El plazo para la construcción y puesta en común de mensajes, negociado con el grupo de alumnos, fue de 45 días con encuentros virtuales quincenales. Momentos únicos de interacción en los que discutimos posibilidades, pensamientos, miedos, indignaciones y compartimos las construcciones con el grupo en su totalidad, inspirando sentimientos de cariño, solidaridad y, como afirma Oscar Jara (2018):

Ejercer la capacidad de comunicarse, la capacidad de escuchar, la capacidad de trabajar en equipo, la capacidad de sentir una profunda indignación ante la injusticia, la capacidad de prever, planificar y proyectar, la capacidad de emocionarse y disfrutar de la belleza, la capacidad de expresarse en múltiples lenguajes, la capacidad de analizar y sintetizar, abstraer y concretar, investigar y movilizar, entre otros (p. 248).

Durante el proceso de construcción y compartición, se observaron algunas dificultades en relación con los mensajes, debido al uso de las tecnologías y al acceso de ellas; tecnologías obsoletas como los celulares con configuraciones básicas que no ayudaban al envío de archivos pesados; estudiantes que, a pesar de aceptar la invitación, no enviaron sus mensajes y no justificaron las razones.

A pesar de que las clases se consideraron normales en términos de número de estudiantes, menos de un tercio del grupo envió mensajes. De dos clases participantes: RRHH con 21 y ADM con 30 inscritos, hablaron 13 alumnas y 1 un alumno. Es importante mencionar

Si bien solo uno de los autores de este artículo es docente en los grupos participantes, el hecho de que los demás trabajen en la misma institución como docentes, los alumnos lo tomaron como conocidos. 
que del total de inscritos, el 70\% participó en las clases a distancia implementadas por la escuela como alternativa para la suspensión de las actividades de aula. El 30\% restante, en ese momento, no utilizaba los entornos virtuales debido a dificultades de acceso y/u otros impedimentos. Estas dificultades revelaron que si bien el mundo avanza hacia entornos donde la tecnología automatiza procesos y virtualiza las relaciones, no todas las personas tienen los recursos para seguir el progreso tecnológico o hacer uso de este.

Los mensajes se realizaron en formato de texto escrito, excepto uno en formato de video, enviado por uno de los estudiantes de RR.HH., en el que participaron esposa e hija. Las construcciones acogidas y compartidas también se almacenaron en un archivo digital y luego se compilaron en una sola presentación.

\subsection{PASO 3: SÍNTESIS}

Para esta etapa definimos que todas las creaciones de los alumnos fuesen reunidas en presentación audiovisual (Power Point), y puestas a disposición con el objetivo de una devolución de los mensajes de forma cíclica; es decir, que cada participante pudiera enviar y recibir mensajes de apoyo para ese momento. Asimismo, pretendíamos que tales construcciones fuesen divulgadas a las personas ${ }^{3}$ involucradas en esta acción con miras a generar recursos para nuevos diálogos y reflexiones sobre la interdependencia humana y el mundo del cual formamos parte (o debemos formar parte) ciudadanos y ciudades. Los retos sobre la sostenibilidad y las siguientes preguntas fueron intencionales: ¿Cómo afecta el escenario actual a todos? ¿Quiénes son los más afectados? ¿Quién sufre más por la pandemia? ¿Cómo nos relacionamos ante este aislamiento social provocado por la cuarentena? ¿Qué soluciones son accesibles y para quién? ¿Cómo podemos re construirnos a nosotros mismos a partir de este escenario? ¿Qué esperar?

Santos (2020, p. 15) propone un análisis de la cuarentena "desde la perspectiva de quienes más han sufrido por estas formas de dominación" y describe quiénes son estos colectivos, a saber: mujeres, trabajadores precarios y autónomos, trabajadores y población de la calle, discapacitados, residentes de las periferias.

Una comunión de destino para las personas que se han ido distanciando a lo largo del proceso social. El distanciamiento denota que los destinos están condicionados a la situación de marginalidad, espacios, condición económica y clase social. Algunas de las cuestiones mencionadas anteriormente se discutieron durante las reuniones a distancia del curso de maestría; ambiente oportuno al escenario para compartir sentimientos como el miedo en relación al desempleo, la preocupación por la brecha en el desarrollo educativo de los niños, la escasez de alimentos, los miedos por la extensión del aislamiento social y sus impactos en la vida de cada uno.

Durante la difusión de los resultados, en una presentación al profesor y a un grupo de alumnos de la maestría, se realizó un ejercicio entre los presentes, el cual consistió en que cada alumno mandara un mensaje de WhatsApp a tres personas de su comunidad, solicitándoles el envío de mensajes requerido a los alumnos, sujetos de este proyecto. El objetivo era crear una analogía entre las dos audiencias (en la misma situación de cuarentena por el coronavirus) sus concreciones y utopías. 


\section{DISCUSIÓN TEÓRICA}

La Educación Popular refleja y en ella subyace la capacidad de socialización, la construcción de la identidad en la autonomía, teniendo al alter ${ }^{4}$ como referente. De esta forma, la alteridad se convierte en mucho más que una constitución física, transpone el espacio y se configura como encuentro. Como dice Jara (2018):

[...] en este contexto, la Educación juega un rol decisivo como factor de socialización, de transmisión de normas morales, de adaptabilidad, pero también de espacio para la constitución de identidad, de forja de autonomía, de conciencia de particularidad en la universalidad, de construcción de capacidades transformadoras, de afirmación de ideales (p. 231).

Encuentro que es una de las características de la Educación Popular. Como afirma Vasconcelos (2020), quitarse la sandalia para que se pueda mostrar la experiencia de la persona. De esta manera, la Educación Popular es un “[...] proceso de humanización, un acto político, de conocimiento y creación, que se da en el diálogo entre los seres humanos, sujetos de su vida, y que, solidariamente, hacen y rehacen el mundo" (Vasconcelos, 2020, p. 02). Por tanto, tenemos como temas fundamentales de la Educación Popular, el diálogo y la participación, los que suceden para denunciar una realidad opresiva y muchas veces excluyente. Como afirma Marco Raúl Mejía (2014):

Así, la educación popular llega al siglo XXI con un acumulado construido en sus luchas por transformar la sociedad y hacer posible la emancipación de todas las formas de dominio que le permiten proponer al mundo de la educación, en sus diferentes vertientes, una concepción con sus correspondientes teorías, propuestas pedagógicas y metodológicas para ser implementada en los múltiples espacios y ámbitos en los cuales se hace educación en esta sociedad. En ese sentido, dota a los educadores críticos de una propuesta para ser implementada en toda la sociedad, bajo el reconocimiento de que hacerlo desde los intereses de los grupos oprimidos y excluidos, permitirá la transformación de esa condición para construir sociedades más justas, más humanas y, ante todo, con una diferencia que no permita la desigualdad y el control por razones de clase, género, etnia, raza, opción sexual, edad, condiciones físicas (p. 75).

A partir de esto podemos decir que nace la construcción de un Ethos, una dirección de la ética, como afirma Leonardo Boff (1999) en su libro Saber Cuidar. Esta dirección ética toma forma "en el marco del sentido de la existencia humana y la búsqueda de su realización en la historia, como instrumento fundamental a ejercitar en el "arte de vivir bien", como destino y como posibilidad; como imperativo y como proyecto" (Jara, 2018, p. 231).

Para que esto suceda, es necesario partir de las condiciones existenciales que se materializan en la vida cotidiana, algunas de ellas construidas por la desigualdad en las relaciones y situaciones, otras impuestas por la situación mundial. La segunda opción se verifica en el momento que enfrenta la población, es decir, la pandemia del Coronavirus. Con Paulo Freire como referente, se puede decir que:

En su etimología la palabra alter se deriva del latín y su significado es otro/a. 
[...] una unidad de época se caracteriza por un conjunto de ideas, concepciones, esperanzas, dudas, valores, desafíos en interacción dialéctica con sus oponentes, buscando la plenitud. La representación concreta de muchas de estas ideas, valores, concepciones y esperanzas, así como los obstáculos para ser más hombres ${ }^{5}$, son los temas de la época (Freire, 2005, p. 53).

El Coronavirus se ha convertido en el tema de la humanidad, desde diciembre de 2019. Sin embargo, incluso con una condición que escapa al dominio de las personas, este hecho se concreta en la intersubjetividad. Apuntando a la humanización y al diálogo que propugna Fabiana Rodrigues de Sousa (2018), es necesaria una búsqueda de la intersubjetividad, en la que y para la cual se apunta el bienestar de todos. Finalmente, una educación que venga de las personas y para las personas en la que tengan la posibilidad de ser vistas y escuchadas con la libertad de poder expresarse, "como un ser cuya condición y posibilidad más legítima es la libertad, como "raíz de toda expresión creadora, así como del pensamiento y la acción política de las personas" (Jara, 2018, p. 237).

Esta acción política apunta a la definición aristotélica de pertenencia a la polis, en la cual, cada persona participa de las condiciones y el sufrimiento de la ciudad, en este caso, tenemos la unidad, esto se materializa en ser afectado por las coyunturas que enfrenta la ciudad. A pesar de que la frase anterior parece real y verdadera, incurre en un error, no considera la diversidad, ya que las condiciones y el sufrimiento se diferencian. A partir de este escenario, se puede decir que la ciudad es escenario de experiencias incluyentes y excluyentes.

Según datos del Instituto Brasileño de Geografía y Estadística (IBGE), la desigualdad en Brasil aumenta todos los días, creando brechas en la educación, consolidándose desde la oportunidad de la primera clase con profesores privados, y la clase subordinada, sin acceso a internet. Así, el privilegio de la ciudadanía se da para algunos mientras que otros piden oportunidades de inclusión.

Boaventura de Sousa Santos (2020) analiza el Estado y las circunstancias actuales agravadas por la pandemia, haciendo una importante correlación entre capitalismo, colonialismo y paternalismo, creando una analogía entre el estado de cuarentena impuesto por el virus pandémico y el estado de cuarentena permanente al que estamos sometidos bajo el yugo del régimen capitalista en su figura dominante: el neoliberalismo.

Para reforzar, Santos (2020) y su propuesta analítica de la cuarentena desde la perspectiva de quienes más la padecen, haciendo énfasis en las mujeres:

La cuarentena será particularmente difícil para las mujeres y, en algunos casos, incluso puede ser peligrosa. Las mujeres son consideradas las cuidadoras del mundo, dominan en la prestación de cuidados dentro y fuera de la familia. Dominan profesiones como la enfermería o la asistencia social, que estarán a la vanguardia de la atención a los enfermos y ancianos dentro y fuera de las instituciones (p. 15).

En su obra Pedagogía del Oprimido, Paulo Freire adopta el sustantivo masculino "hombre" para representar a la humanidad, hombres y mujeres; una nomenclatura que ha recibido varias críticas por parte del movimiento feminista, lo cual ha provocado reflexiones que alteran su conducta de escritura en futuras obras cuando comenzó a mencionar a las mujeres como un género distinto. 
Más aún, en un escenario de patriarcado violento, el hecho de estar en casa, sin contacto social, bajo el yugo del agresor, puede ser el agravante de un ciclo interminable de violencia. ¿Y los de la calle? ¿Cómo será la cuarentena para quienes no tienen hogar? Personas sin hogar, abandonadas, que pasan la noche en los viaductos, en estaciones de tren o metro, en túneles de agua de lluvia o túneles de alcantarillado en tantas ciudades del mundo. En Estados Unidos los llaman "gente del túnel”; ¿Cómo será la cuarentena en los túneles?, ¿no han sido puestos en cuarentena toda su vida? (Santos, 2020, p. 17).

Ante este escenario, ¿qué se puede hacer? ¿Qué caminos encontrar? ¿Cómo hallar caminos ante un sistema maniqueo capaz de traer y generar exclusiones de manera intrínseca? En ese sentido, nos proponemos adentrarnos en esta reflexión desde algunas referencias, pero principalmente, en cierto modo, en la Educación Popular.

Danilo Streck (2018) en su artículo Descolonizando la participación - Lineamientos para una pedagogía crítica latinoamericana busca "mostrar cómo la educación popular se entrelaza en los movimientos de la sociedad que buscan la democratización a través de la participación, lo cual, a su vez, es una condición para la formación y ejercicio de la ciudadanía" (p. 160). Esta se constituye de manera colonial, pero también puede ser descolonial ${ }^{6}$, ya que forma parte del proceso de reflexión que requiere una mirada atenta a América Latina y su diversidad, buscando diálogos de singularidad, una concepción freiriana.

Streck, (2018), plantea la siguiente pregunta: “¿de qué es, efectivamente, ser parte?” (p. 162). De esta manera, el autor trae el concepto, principalmente en torno al derecho a escuchar y ser escuchado. Actitud que buscamos en este proyecto: actitud de escuchar al otro y ser capaz de proporcionar escucha y habla, teniendo como referencia el pensamiento descolonial en el que el tiempo se convierte en elecciones hacia el otro.

En una segunda propuesta reflexiva, el autor informa que "la participación se aprende participando" (Streck, 2018, p. 165). Por ello, buscamos escuchar en nuestro caso los discursos y deseos de los alumnos del curso técnico de RRHH y ADM, y cómo estos alumnos se pueden constituir haciendo y participando.

Con ello, comprobamos la importancia primordial de esta propuesta de intervención socio comunitaria, ya que es coherente con nuestra práctica diaria, especialmente en lo que se refiere a la participación efectiva y descolonial, en la que y por la cual las percepciones deben ser precisas. Entre ellos: ¿cómo está siendo efectiva la participación entre los estudiantes? ¿Cómo, a través de la diversidad de cada alumno, enfrenta la situación de empleo, desempleo, estudio, entre otros?

Para ello es necesario mirar, percibir el mundo que nos rodea y su historicidad y una de las grandes vías para eso es la Educación Popular. En este sentido, el diálogo respetuoso y empático se convierte en el fundamento de la intersubjetividad y, así, nos preguntamos: “¿qué tipo de diálogos estamos construyendo?”. Después de todo, el verdadero diálogo requiere participación. Abrimos así el escenario para la profundización del significado: participar.

Según Vasconcelos (2020), participar es estar con, sin embargo, hablar de participación no es, por tanto, promover la participación. Es posible observar la recurrencia de algunas actividades que acontecen en la artificialidad, lo que conduce a técnicas y dinámicas

Tomando a Ballestrin (2013) como marco, se puede decir que la descolonialidad es la capacidad de pensar y actuar sin el marco que surge de las colonias. De esta forma se tiene en cuenta la diversidad, el negro, la mujer, los indios, entre otros. 
ineficientes para un momento participativo de los estudiantes. La pregunta principal es: “¿por qué participar?” Teniendo como referencia al filósofo Martin Buber (2001) y la relación de mí-tú, es fundamental afirmar que la participación es relacional, de confianza y convivencia.

En la participación efectiva, la persona puede interferir en la realidad, deshacerla y reconstituirla, en autonomía. Es un compromiso mutuo. Basándonos en esto y teniendo como referencia a Valéria Vasconcelos (2020), es importante la tarea de estrechar los lazos a través del diálogo y la participación, sin perder la criticidad. De esta manera, se materializa en un proceso democrático, de diversidad de opiniones, que crea lazos de amor. Este fue nuestro referente consolidado en la propuesta de los mensajes y la escucha a los alumnos.

El pensamiento antes mencionado se materializa de manera micro, pero puede llegar de manera macro, a través del Estado. Toda nuestra reflexión no significó olvidar las tareas del Estado, que debe jugar el papel de esta población escuchando, actuando desde el cuidado. Sin embargo, ante las vicisitudes cotidianas, lo que nos trae los rostros de los estudiantes para poder trascender y demostrar caminos de liberación y transformación a través de la educación.

Al fin y al cabo, la educación es una praxis que apunta a mirar la realidad, más aun, según Freire (2005), su transformación. Después de todo, la calidad que la educación busca y subyace en cada persona como ser humano que es "capaz de adquirir conocimientos y habilidades para adaptarse a diferentes condiciones ambientales o de su propia existencia y modificar su comportamiento; en definitiva, una cualidad que puede ser objeto de aprendizaje" (Jara, 2018, p. 237).

Por lo tanto, el desafío en este período epidémico es convertirse en una persona de alteridad. Para ello, utilizamos los medios disponibles en la actualidad según la situación, es decir, internet. En este pequeño gesto, parafraseamos a Paulo Freire frente a la educación, o sea, la educación liberadora no cambia el mundo, sino que prevé que la gente pueda cambiarlo.

Refiriéndonos a Jara (2018, p. 252), esperamos que todas las personas involucradas, participantes e impactadas por el trabajo de los estudiantes de RRHH y ADM, puedan "crear otras sensibilidades, e imaginar otros escenarios, rompiendo los límites actuales", y tengan energía e inspiración para llenarse de esperanza en días mejores.

La energía inspiradora, que se convierte en motivo de una acción eficaz y transformadora, impregnada de la energía propia de cada uno, retratada por Freire (2002):

Para los seres humanos, como seres en la praxis, transformar el mundo, proceso en el que también ellos se transforman, significa impregnarlo de su presencia creadora, dejar en este las huellas de su trabajo. La criticidad y los propósitos que se encuentran en las relaciones entre el ser humano y el mundo implican que estas relaciones se dan en un espacio no solo físico, sino histórico y cultural (p. 81).

De lo anterior se percibe la importancia de este estudio, especialmente para nosotros los investigadores, que podamos consolidar el encuentro con el otro a través del diálogo y la participación descolonial, respetando a la persona en su singularidad, diversidad, opinión y contexto histórico. 


\section{RESULTADOS}

El momento histórico que vivimos por la pandemia del COVID-19, revela un escenario de incertidumbres, inseguridades y desigualdades cada vez más visibles. Tememos el hambre, el desempleo, la falta de recursos económicos, la separación de los seres queridos, quizás para siempre; tememos al futuro. La sensación de vivir en un organismo al borde del colapso no es un privilegio individual, es un miedo colectivo, aunque en diversos grados.

La experiencia de acercamiento con los alumnos de los cursos Técnicos, asignaturas de este estudio y también el aporte de los compañeros de la maestría, durante la presentación de nuestro estudio, nos dio motivos para reflexionar sobre la realidad que impregna a todos. En una metáfora compartida por Valéria Vasconcelos, profesora de la disciplina de la maestría donde se originó este estudio, "la tormenta es la misma, pero los barcos son diferentes". Hay personas en botes gigantes con lujosas comodidades, hay pequeños sin estructura para enfrentar la tormenta, hay personas remando en canoas.

La propuesta de acercarnos a los alumnos de los cursos Técnicos nos permitió practicar la escucha de sus concreciones y utopías, esperanzas y sentimientos; y es precisamente en este punto donde se unifica la Educación Popular, después de todo. La experiencia latinoamericana denota la capacidad de celebrar el diálogo y la participación, perteneciendo a diversos escenarios.

Basado en Crenshaw (2002), al dialogar con Hannah Arendt, denota la capacidad de ser/de llegar a ser, esto se puede realizar a través de las palabras, no es algo dado, es relacional, el ser se co-crea y convive; así, el pensamiento no se institucionaliza ni se referencia, sino que se construye desde la diferencia, el diálogo y la convivencia con el otro. De esta forma se puede plantear el axioma: somos coexperiencia y coexistencia.

La búsqueda de ayuda comenzó con los grupos del curso Técnico, pero sabemos que era solo el comienzo de un resultado que no podía terminar ahí, por lo que pronto pensamos cuánto podrían nuestros compañeros, alumnos y estudiantes de la maestría contribuir a este momento de reflexión. Por supuesto, ellos nos extendieron rápidamente una mano virtual fantástica, compartiendo un enlace de plataforma con sus contactos, a través de WhatsApp.

No obstante, sabemos que internet y los teléfonos inteligentes no son para todos, y lamentablemente en ese momento no pudimos conseguir ninguna otra forma de envío que no fuera a través de este canal, ya que teníamos un tiempo limitado para buscar resultados. Grandes reflexiones, un sentimiento de impotencia ante quienes nos gustaría haber escuchado, pero que fueron silenciados por el aislamiento social.

De esta forma, adquiere una importancia primordial las políticas públicas dirigidas a los que se encuentran en la periferia de la ciudad, a los subordinados como los llama Valla (1996). Al fin y al cabo, metafóricamente hablando, estamos en el mismo barco de la ciudad, sin embargo, algunos tienen botes, chalecos salvavidas o han aprendido a lo largo de la vida a nadar con los mejores maestros; en cambio, a otros no les han enseñado a nadar, no tienen chalecos ni botes, e incluso tienen pesos que incluso pueden ayudarlos a hundirse.

La educación popular se vuelve fundamental en el diálogo con la realidad, anunciando y denunciando injusticias y opresiones, en la búsqueda de un mundo más justo e igualitario. 


\section{CONCLUSIONES}

Vasconcelos en su artículo "Diálogo y participación en la educación popular: mucho más allá de la teoría” (2020), comienza por rescatar la actitud de quitarse la zapatilla para entrar en los hogares de las personas, en el caso del autor, específicamente, en los hogares de personas de la Amazonía brasileña. Quitarse las sandalias, pantuflas, zapatos es remoto y pertenece a muchas tradiciones.

Al permitirnos reflexionar sobre este escrito, encontramos que hay momentos en nuestra historicidad en los que nos despojamos de lo que nos protege.

Desnudarse puede ser signo de debilidad, miedo, recelo o incluso impedimento, pero, refiriéndose a la cultura amazónica, se convierte en respeto y limpieza, con los pies en la tierra. Tocar el suelo puede traer la referencia de nuestra humanidad, perteneciente a la Tierra, que, como dice Leonardo Boff (1999), es más que un planeta, es Gaia, la gran madre. Madre que acoge a todos y todo sin discriminar a nadie y ofrece lo mejor que puede tener y ser. Sin embargo, quienes se encuentran en ella pueden vivir sin la capacidad de desapego, lo que provoca una cuarentena ad eternum en quienes ni siquiera tienen sandalias para desvestirse. De esta forma, el mundo es desigual y excluyente, y la educación popular tiene la propuesta de denunciarlo a partir del compromiso con los más devaluados, contra una sociedad que prioriza el capital sobre el humano, como afirma Méjia (2014). Específicamente, la pandemia se presenta como el nuevo escenario de la época; sin embargo, trae, concreta y acentúa viejos escenarios como la exclusión.

Las personas que viven sin la capacidad de desapego, en cambio, pueden tener la falsa sensación del infinito, porque creen que el poder de poseer puede vencer al de existir. Pero, como afirma Heidegger (2016), hay momentos en los que la vida nos enfrenta con la demostración de la finitud, que sin importar el color, raza, género, clase social, entre otros, pertenecemos a una vida límite. Por eso, vale la pena reflexionar sobre lo que estamos haciendo, construyendo y siendo. En vista de esta reflexión, es posible que no estemos teniendo lo que para Heidegger (2005) es nuestra excelencia en el cuidado de estar-enel-mundo. Boff (1999) afirma que el cuidar es el ethos del ser humano. Sin embargo, observamos que, en un mundo capitalista, cada vez más, se cuida menos. Cuidamos menos la vida, el otro, los ancianos, los negros, los niños, las mujeres, la gente de la calle, la ecología, los cercanos, los lejanos, entre otros. La vida trae momentos para detenerse y reflexionar. La comunicación no violenta, el respeto por los demás y la empatía deben ser nuestra ética, especialmente, como afirma Santos (2020), para quienes pertenecen a la cuarentena interminable provocada por un virus que acompaña a la humanidad desde hace décadas, a través de un sistema que mata y excluye: la indiferencia.

En este sentido, la educación popular también necesita ser reinventada; al fin y al cabo, se centra en la relación, la escucha, el ser y el estar con el otro y ¿cómo hacer que esto se materialice en un mundo aislado? Esto se convierte en un gran desafío; la unidad, no en el sentido de uniformidad, sino de respeto al ser humano en su concreción. Esta investigación buscó conocer a la persona, aunque sea remota, pero ¿cómo serán las relaciones en un escenario que decepciona? ¿Cómo escuchar a los excluidos con una herramienta también exclusiva, la tecnología? Este artículo buscó aportar pistas para la concreción de este proceso, pero son necesarios más investigaciones y estudios relacionados con este tema, los cuales deben conducir no solo a la denuncia, sino al propósito de la Educación Popular, para cambiar. Como afirma Méjia (2014): 
Implica una opción básica de transformación de las condiciones que producen la injusticia, la explotación, dominación y exclusión de la sociedad. En ese sentido, se inscribe en la tradición que reconoce que si las desigualdades son producidas socialmente, de la misma manera pueden ser enfrentadas y solucionadas. En esta perspectiva, la tarea de la transformación de esas condiciones de injusticia, es una tarea de quienes sufren estas situaciones, pero también de quienes teniendo condiciones económicas, sociales y culturales distintas consideran que aquélla es una condición que debe ser enfrentada no sólo por los sujetos que viven directamente la dominación y sus efectos, sino por toda la sociedad, para construir relaciones sociales basadas en la solidaridad. Propone un trabajo pedagógico que reconociendo los intereses de los grupos sociales empobrecidos política, económica y socialmente, los coloque en la sociedad para hacer real el aprendizaje situado en una perspectiva crítica y de reconocimiento, de construir las condiciones para transformar esa condición (p. 6).

De manera especial, se puede decir que los estudiantes de RRHH y ADM hicieron de manera micro lo que se espera de una forma macro como humanidad: mirar a otro.

\section{REFERENCIAS BIBLIOGRÁFICAS}

Ballestrin, Luciana (maio - agosto 2013). América Latina e o giro decolonial. Revista Brasileira de Ciência Política, (11). Brasília, 89-117.

Boff, Leonardo (1999). Saber Cuidar: ética do humano - compaixão pela terra. $2^{\circ}$. ed. Petrópolis RJ: Vozes.

Buber, Martin (2001). Eu e Tu. Tradução do alemão, introdução e notas por Newton Aquiles Von Zuben. 10. ed. São Paulo: Centauro, 170.

Crenshaw, Kimberlé. (2002). Documento para o encontro de especialistas em aspectos da discriminação racial relativos ao gênero. Estudos feministas, ano 10, pp. 171-188, 1/2002.

Freire, Paulo (2005). Pedagogia do Oprimido. 42 a ed. Rio de Janeiro, Paz e Terra. . (2002). Ação cultural para a liberdade. Rio de Janeiro: Paz e Terra.

Heidegger, M. (2005). Ser e tempo. Márcia Sá Cavalcante Schuback (trad). 15 ed. Petrópolis: Vozes.

Jara, Oscar Holliday. (2018). Aportes de los procesos de Educación Popular a los procesos de cambio social. In: Quintar, Estela, Guelman, Anahí, Salazar, Mónica \& Cabaluz, Fabián (coord.). Educación popular y pedagogías críticas en América Latina y el Caribe: corrientes emancipatorias para la educación pública del Siglo XXI. 1a ed. - Ciudad Autónoma de Buenos Aires: CLACSO. Libro digital, Pdf. 221-252.

Larrosa-bondía, J. (2002). Notas sobre a experiência e o saber de experiência. Revista Brasileira de Educação, (19), 20-28. https://dx.doi.org/10.1590/S1413-24782002000100003

Mejía, M. R. J. (2014). La Educación Popular: Una construcción colectiva desde el Sur y desde abajo. Arquivos Analíticos de Políticas Educativas, 22(62). http://dx.doi.org/10.14507/epaa. v22n62.2014.

Santos, Boaventura de S. (2020). A cruel pedagogia do vírus. Coimbra: Portugal, Ed. Almedina S.A. Sousa, Fabiana Rodrigues de. (2018). Legado freireano, feminismos e prostituição: desvelando o político-pedagógico na pesquisa em educação. Educação Unisinos, 22(4), 324-333, Disponível em: http://revistas.unisinos.br/index.php/educacao/article/view/edu.2018.224.10

Streck, Danilo R. (2018). Descolonizar a participação. Pautas para uma pedagogia crítica latinoamericana. In: Quintar, Estela, Guelman, Anahí, Salazar, Mónica, \& Cabaluz, Fabián (coords.). Educación popular y pedagogías críticas en América Latina y el Caribe: corrientes 
emancipatorias para la educación pública del Siglo XXI. 1a ed. - Ciudad Autónoma de Buenos Aires: CLACSO. Libro digital, Pdf. 159-172.

Torrezan, Rosiane Morais. (2012). Educação popular e pesquisa qualitativa: considerações sobre a utilização dos métodos da pesquisa-ação e da pesquisa participante na educação, Boletin GEPED - Ano I, 1(1), 25-35, dez. 2012, disponível em http://docs.fct.unesp.br/grupos/gepep/3a.pdf

Trivinos, Augusto Nibaldo Silva (1987). Introdução à pesquisa em ciências sociais: a pesquisa qualitativa em educação / Augusto Nibaldo Silva Trivifios. São Paulo: Atlas.

Valla, Victor Vincent. (1996). A crise de interpretação é nossa. Educação e Realidade, 21(2), 177190.

Vasconcelos, Valéria Oliveira de (2020). Diálogo e participação na Educação Popular: muito além da teoria. Em: Ação socioambiental na Amazônia: educação, saúde e economia em comunidades. São Paulo: Editora Na raiz. . (1980). Totalidade e infinito. Tradução de José Pinto Ribeiro. Lisboa: Edições70. 